\title{
Original
}

\section{Ultrastructural Study of the Cardiac Ganglia in Prenatal Rat II. Axon Terminals, Satellite Cells and Small Granular Cells}

\author{
Keh-Min LIU ${ }^{1)}$ and Seiichiro INOKUCHI ${ }^{2)}$
}

\begin{abstract}
Prenatal development of the preganglionic nerve endings, satellite cells, and small granular cells in the cardiac ganglia of fetal rat were studied by electron microscope. Ganglia from 14-16, 18, and 20-21-day-old fetuses were investigated. In the developing cardiac ganglia, three types of afferent axon terminals could be recognized distinctly. The type I axon terminals contained small clear vesicles only, and appeared earliest in the 14-day-old fetus. Type II axon terminals contained numerous small clear vesicles and few large dense-core vesicles, and these may be cholinergic nerve endings of vagal origin. The type III axon terminals were characterized by the presence of glycogen granules, small clear vesicles, and numerous large dense-core vesicles, which may be afferent adrenergic nerve endings of sympathetic origin. Type II and Type III axon terminals could be observed at approximately day 15 of gestation. The development of axosomatic synapses was earlier in synaptogenesis than that of axodendritic synapses. Young satellite cells were characterized by large round nuclei and thin cytoplasm layers with a paucity of organelles. Few short cytoplasmic processes projected from the cell bodies. In mature satellite cells, the nuclei were semilunar in shape and were surrounded by little cytoplasm. Numerous branched cytoplasmic processes extended from the cell bodies to enwrapp the principal ganglion cells. The maturation of small granular cells could be divided into three stages: early immature, young, and mature. Three different types of granular vesicles appeared in the periphery of their perikaryon. In the developing cardiac ganglion of the prenatal rat, mitotic small granular cells were frequently encoutered, but only a few mitotic satellite cells were observed.
\end{abstract}

Key words: fetal rat, cardiac ganglia, synaptogenesis, small granular cell

\section{Introduction}

In mammals, all sympathetic and parasympathetic ganglion cells have a common embryonic origin in the neural crest. The cardiac ganglia were parasympathetic ganglia derived from the cervical neural crest cells which migrated to the heart analogue in early embryogenesis ${ }^{1,2}$. However, due to the difficulty of identification, and the diffuse spread of the cardiac ganglion cells in uterine animals, only few morphological studies have been performed in the prenatal rat $^{3)}$, the fetal rabbit ${ }^{4,5)}$, the chick embryo ${ }^{6)}$, and the human fetus ${ }^{i-9)}$. Although, in uterine animals, it is well known that the cardiac ganglion consists of principal nerve cells, satellite cells, small granular cells, nerve bundles, and blood capillaries ${ }^{5)}$, in the cardiac ganglion of

1) Department of Anatomy, Kaohsiung Medical College, Kaohsiung, Taiwan, Republic of China.

2) Department of Anatomy, Showa University School of Medicine, 1-5-8 Hatanodai, Shinagawa-ku, Tokyo 142, Japan. 
prenatal rats, only the principal nerve cells have been investigated"). Little attention has been paid to the prenatal development of afferent axon terminals, the early formation of synapses, and the maturation of satellite cells in the cardiac ganglion. Papka ${ }^{5,10)}$ reported that ultrastructure of small granular cells appeared to change little as development of the rabbit ganglia progressed. In our serial studics of the prenatal development of rat cardiac ganglia, localization of ganglion cells and their topographical relations with surrounding structures were reported ${ }^{11}$, and differentiation and the maturation of undifferentiated cells into the neuron were described"). In the present investigation, development of preganglionic axon terminals, synaptogenesis, satellite cells, and small granular cells in the cardiac ganglion of rat fetus were studied by electron microscopy.

\section{Materials and Methods}

Adult male and estrus female Sprague-Dawley rats were mated overnight, and the day after mating was considered to be day zero of gestation (D0). For studies of prenatal rats, the pregnant females were anesthetized with sodium pentobarbital $(40 \mathrm{mg} / \mathrm{kg}$, i.p.) and laparotomized. The fetuses were removed one by one from the uterus, starting from the most lateral fetus of either uterine horn and proceeding medially, one horn at a time. Fetuses were selected for study at $14-16,18,20$ and 21 days of gestation. The embryo was anesthetized hypothermically and perfused transcardially with cold fixative by the method of Abrunhosa $^{12)}$.

For study by electron microscope, the fixative was a mixture of $2 \%$ paraformaldehyde, $2 \%$ glutaraldehyde, and 2\% PVP (polyvinylpyrrolidone) in $0.1 \mathrm{M}$ cacodylate buffer solution at $\mathrm{pH} 7.4$, containing $0.04 \% \mathrm{CaCl}_{2}$. The fixative was freshly prepared and filtered just before use. After perfusion, the whole heart of the fetus was removed and immersed in fresh fixative, and kept in the refrigerator overnight. The following morning, the atrial portion of the heart was trimmed into $1 \mathrm{~mm}^{\prime \prime}$ pieces, postfixed in $1 \%$ osmium tetroxide solution for 2 hours, dehydrated in graded ethanol and propylene oxide, and finally embedded in Araldite 502.

One-micron thick sections were cut and stained in $1 \%$ borated toluidine blue, and scanned with a light microscope to located the cardiac ganglion cells. After the ganglion was found, the bleck was trimmed and ultrathin sections were cut by an ultramicrotome. The serial ultrathin sections were placed on a copper grid and double stained with uranyl acetate and lead citrate. Stained sections were then observed and photographed by use of a Hitachi H-500 electron microscope.

\section{Results}

1. Synaptogenesis and Axon Terminals in Developing Cardiac Ganglia

Early signs of synapse formation were observed in the cardiac ganglia of rats at 14 days of gestation, where a developing preganglionic axon terminal closely approached the soma of a neuroblast (Fig. 1). At the contact site, neither presynaptic nor postsynaptic membranous thickness could usually be observed. Occasionally, a thin osmiophilic zone was observed on the plasmalemma of two contacted sites, however, no synaptic vesicle appeared in the axon terminal (Fig. 1). On the other hand, some axon terminals made synaptic contact with short dendritic processes that projected from neuroblast soma (Fig. 2). Within some axon terminals, there were a few small clear vesicles, resembling synaptic vesicles, located close to the 
osmiophilic zone (Fig. 2).

In cardiac ganglia from fetal rats at 16 days of gestation and older, developing and well developed synapses with more synaptic vesicles were seen. Deposition of more electrondense material appeared on the synaptic sites of axon terminals and neuroblasts (Fig. 3). The early synaptic vesicles often varied in size and form. In early developing synapses, only small clear vesicles $(40-60 \mathrm{~nm}$ diameter) were present in the axon terminals. In well developed synapses, one type of axon terminals contained some small clear vesicles and few large dense-core vesicles (80-120 nm diameter) (Fig. 4), and another type contained glycogen granules, small clear vesicles, and large dense-core vesicles (80-120 nm diameter) (Fig. 5).

Frequently, axon terminals containing some small clear vesicles and a few large dense-core vesicles formed axosomatic synapses. On the contrary, axon terminals that contained mitochondria, glycogen granules, small clear vesicles, and large dense-core vesicles usually formed axodendritic synapses. However, axon terminals containing both clear and dense-core vesicles could be found scattered among the ganglion cells, or amid the ganglionic neurophil with no apparent synaptic contact with the ganglion cells (Fig. 6).

Although, both axosomatic and the axodendritic contacts could be observed in the cardiac ganglia of day 14 fetal rats, the appearance of desmosome-like structures between the axon terminal and the soma of neuroblasts, which were characteristic of the axosomatic synapses, appeared earlier than in axodendritic synapses. The contact sites of axosomatic synapses were symmetrical, but those of axodendritic synapses were asymmetrical, and the osmiophilic active zone of the postsynaptic site was thicker than that of the presynaptic site.

2. Development of Satellite Cells in Developing Cardiac Ganglia

In the cardiac ganglia of the day 14 fetal rats, the satellite cells could be easily recognized. The earlier identifiable satellite cells were irregular in shape and consisted of a large, round or oval nucleus and a thin layer of cytoplasm. The chromatin substance in the centrally located nucleus was unevenly dispersed. One or two nucleoli were present in the nucleus. The cytoplasm contained organelles of free ribosomes, polysomes, lipid droplets, long cisterna of rough endoplasmic reticulum, and few mitochondria (Fig. 7). The Golgi complex was seldom encountered in the young satellite cell, but it occurred with greater frequency in the mature ones. In the early developmental stages, the cytoplasmic processes extended from the young satellite cells were few and short. Coincidently, cnly a few mitotic satellite cells could be observed.

The mature satellite cell was spindle or irregularly shaped and possessed a semilunar or spindle shaped nucleus which was surrounded by a thin layer of cytoplasm. The chromatin substance was heterogeneously dispersed in the nucleus (Fig. 8). Few organelles, such as polysomes, lipid droplets, microtubules, single cisterna of rough endoplasmic reticulum, and Golgi complex, were found in the thin cytoplasm. However, numerous cytoplasmic processes projected from its cell body and branched extensively. These processes surrounded the cell bodies of neuroblasts, immature neurons, small granular cells, and preganglionic axon terminals. The structures of desmosome or puncta adherens appeared between the satellite cells and neuroblast cell bodies, as well as between the satellite cells and nerve fibers (Fig. 8). 3. Development of Small Granular Cells in Developing Cardiac Ganglia

In the cardiac ganglia of day 14 fetal rats, the early immature small granular cells were irregularly shaped, larger in size, and contained more cytoplasmic organelles than the undifferentiated cells (Fig. 9). The moderately electron-dense nuclei were irregular in profile, 
and contained unevenly distributed chromatin. One or two eccentric nucleoli were situated close to the nuclear membrane. In the cytoplasm, there were polysomes, centrioles, a few mitochondria, and some rough endoplasmic reticulum. Several groups of well developed Golgi complexes appeared close to the nucleus (Fig. 9). The most characteristic structure of a cell was the presence of some 120-140 nm diameter vesicles, which contained electron opaque, homogeneous cores (Fig. 9). Occasionally, short cytoplasmic processes extended from the cell body.

The young small granular cells were round to oval in shape, and contained round to ovoid nuclei in which the perimembranous rim of chromatin was prominent. The cytoplasm contained more well developed organelles, such as polysomes, Golgi complexes, multivesicular bodies, centrioles, and mitochondria. Numerous granular vesicles were distributed along the peripheries of the cell bodies (Fig. 10). The dense cores of some granular vesicles were eccentric and in contact with the surrounding membrane (Fig. 11). Simultaneously, some short processes extended from the cell bodies. The cells were consistently attached by adjacent small granular cells and some nerve fibers. Both clear and dense-core synaptic vesicles were observed in the axon terminals (Figs. 12A, 12B).

The mature small granular cells were irregularly shaped, and contained more granular vesicles than the young small granular cells. The centrally located nuclei were oval or round, and contained homogeneously distributed chromatin. The nucleoli were eccentric and attached to the nuclear membranes (Fig. 13). Polysomes, short rough endoplasmic reticulum, numerous mitochondria, well developed Golgi complexes, and granular vesicles appeared in the less electron-dense cytoplasm. These granular vesicles were large (160-300 nm) and located in the peripheries of the cell bodies (Fig. 14). Some nerve fibers closely abutted to the small granular cells and formed synapses. In these presynaptic axon terminals, small clear vesicles and large dense-core vesicles were found (Figs. 15, 16). Cytoplasmic processes of satellite cells branched and enveloped the cell bodies of the small granular cells and axon terminals (Fig. 15). Dividing small granular cells with granular vesicles were also observed (Fig. 17).

\section{Discussion}

1. Synaptogenesis and Axon Terminals in Developing Cardiac Ganglionic Cells

Synaptogenesis in the central nervous system is a well studied process. However, little informations has been reported about synapse formation and differentiation in the prenatal developing cardiac ganglia ${ }^{i}$. There are different concepts of which structure appear first in developing synapses. Rees et al. ${ }^{13)}$ reported that in "in vitro" studies, osmiophilic material was present on the cytoplasmic sides in both pre- and postsynaptic neurons and was the first specialized component in forming synapses. On the other hand, Okado ${ }^{14)}$ observed the spinal cord of human embryo and reported that in $10 \mathrm{~mm}$ embryos, the first synapses contained small numbers of synaptic vesicles and asymmetrical membrane thickenings, with postsynaptic membranes thicker than presynaptic ones. However, he also reported that in $11 \mathrm{~mm}$ human embryos, the initial of synapse formations contained small numbers of synaptic vesicles and prominent presynaptic membrane densities ${ }^{14)}$. Hervonen ${ }^{15)}$ reported that the development of synapse in the adrenal medullas of human fetuses were started with the accumulation of synaptic vesicles, and were then followed by the appearance of membrane thickening. In developing cardiac ganglia of fetal rats, the earliest sign of synaptogenesis was close contact of axon terminals with the soma of undifferentiated cells or neuroblasts, and was devoid of any 
specialization. With the development of nerve elements, the osmiophilic zone appeared first on both membranes of contact sites, which were symmetrical in density. However, typical synaptic vesicles were not yet found in the axon terminals. This short paramembraneous electron-dense material may represent the beginning of synapses, which agrees with the descriptions by Bunge et al. ${ }^{16)}$, and Shvalev and Sosunovi), that presynaptic and postsynaptic membrane thickening precedes the accumulation of synaptic vesicles.

It was reported by Shvalev and Sosunovi) that of the early synapses in cardiac ganglia of human fetuses the axodendritic type are predominant. On the other hand, Papkas) found simultaneous appearance of axodendritic and axosomatic synapses in the cardiac ganglia of rabbit fetuses. In our study, the development of axosomatic synapse was earlier than that of axodendritic synapses. It has been reported that, in human fetal cardiac ganglia, the dendritic spines of ganglion cells often invaginated into the axon bulging and formed axodendritic synapse ${ }^{i}$, but we failed to vnd such of synapses in our study.

With further development, more synaptic vesicles were found in the presynaptic axon terminals. It was reported by Kirby $e t$ al. ${ }^{6)}$ that in developing cardiac ganglia, most of the processes observed initially during the migrating phase were preganglionic axons. In that study, the preganglionic axon terminal were divided into 3 categories according to the types of synaptic vesicles. During the early developmental stage, these preganglionic axon terminal contained small clear vesicles only, and were classified as type I axon terminals. The type II axon terminal contained numerous small clear vesicles and a few large dense-core vesicles, which was similar to those described by Richardson ${ }^{1 i)}$ as cholinergic synapse of vagal origin. The dense-core vesicles found in the axons and axon terminals suggested that they were synthesized in more proximal parts of the axons or in the cell bodies and transported to the distal axon terminals.

The third type of axon terminal was filled with a few glycogen granules, some small clear vesicles, and some large dense-core vesicles. This type of terminal was an afferent adrenergic nerve ending. After being treated with 5-hydroxydopamine, most of the small clear vesicles were transformed into small dense-core vesicles ${ }^{5)}$. Synaptic contact between the preganglionic adrenergic axon terminals and the parasympathetic postganglionic cholinergic cells also appeared in the enteric plexus ${ }^{18)}$ and atrial ganglia ${ }^{19)}$. The adrenergic terminals may affect, either directly or indirectly, the inhibitory phenomena in the cardiac ganglia ${ }^{5)}$.

Sensory nerve terminals, which contain osmiophilic lamellar bodies, numerous mitochondria, glycogen particles, and pleomorphic vesicles, have been reported in the cardiac ganglia of human fetuses ${ }^{7,20)}$. They were not observed in the developing cardiac ganglia of fetal rat pups. Since the development of motor fibers was earlier than that of sensory fibers in the spinal cord ${ }^{21)}$, it can be considered that cholinergic and adrenergic nerve fiber innervation of the cardiac ganglia of the fetal rat was earlier than sensory fiber innervation.

2. Development of Satellite Cells in Developing Cardiac Ganglia

Until now, there has been little information about the development of satellite cells in cardiac ganglia. In the earliest cardiac ganglion studied, the irregular shaped satellite cells were characterized by large, irregular shaped nuclei, few cell organelles, and poorly developed cytoplasmic processes. It can be easily recognized that differentiation of the satellite cell in the ganglia began earlier than that of ganglionic nerve cells, as reported by Papka ${ }^{10)}$. In the more mature satellite cells, the nuclei were elongated, and the cytoplasmic processes were numerous and extensively branched. They partially enveloped the cell bodies of neuroblasts, 
immature neurons, small granular cells, and preganglionic axon terminals. The thin sheetlike processes of mature satellite cells passed completely over the perikarya of late immature neurons, intermingled with their short dendritic processes and pre-synaptic axon terminals, and formed complex multilayered zones. Similar complex structures were also found in the cardiac ganglion of adult rat ${ }^{19)}$. From this study, it can be assumed that maturation of the satellite cells and surrounding of the perineuronal sheath were correlated with the differentiation and maturation of the cardiac ganglion cells.

\section{Development of Small Granular Cells in Developing Cardiac Ganglia}

In sympathetic ganglia, the small granular cells were considered to have originated from undifferentiated cells ${ }^{10}$. In cardiac ganglia of 14 day fetal rats, early immature small granular cells possessed characteristic structures similar to those of the intermediate cells in sympathetic ganglia, and confirmed Papka's observation ${ }^{10)}$. Furthermore, even as early as the fourteenth day of gestation, there were several groups of well developed Golgi complexes in the perikarya of the early immature granular cell. This showed that the beginning of differentiation of the small granular cell was earlier than that of the neuroblast, and served as a source of catecholamine during the early development ${ }^{10)}$.

Coinciding with the development and maturation of the small granular cells, both the number and size of the granular vesicles increased. However, most of them were distributed in the peripheries of cell bodies. Similar observations were also described in the small granular cells of developing sympathetic ganglia ${ }^{10)}$ and the chromaffin cells of developing adrenal medulla ${ }^{22)}$.

There is much data on the size of granular vesicles, and on the size, form, electron density and positioning of their contents. It was summarized by Taxi et $a .^{23)}$ that there are 5 types of granular vesicles found in small granular cells in adult animals. However, in our study of prenatal rat, only 3 types of granular vesicles in the small granular cell could be easily recognized: Type I granular vesicles were $130-160 \mathrm{~nm}$ in diameter, with a centrally located core of moderate to high electron density and a thin rim like a halo. This type of granular vesicle is a storage site for dopamine ${ }^{24}$. Type II granular vesicles were 150-300 nm in diameter, with a dense to highly dense core. The eccentrically located nucleus was consistently fused with the membranes of granular vesicles. This type of granular vesicle is a storage site for noradrenaline ${ }^{23)}$. Type III granular vesicles were approximately 120 to 300 $\mathrm{nm}$ in diameter, contained a granular core with a spongy appearance of medium density. The granular vesicle had a heterogeneous structure and was considered to be an adrenalinestoring granular vesicle ${ }^{25}$.

It was reported by Papka $^{5)}$ that there are no synaptic contacts in the developing small granular cells of prenatal rabbit cardiac ganglia. In our study, however, axon terminals contained presynaptic vesicles and formed synapses with the perikaryon of young and maturing small granular cells. As in our previous description of the synaptogenesis of cardiac ganglionic cell in this study, there were also three of the same types of axon terminal to be seen in contact with, or close to the small granular cells. The type II and type III axon terminals, which represented cholinergic and adrenergic nerve ending, respectively, were found more frequently than type I. Except for those of vagal origin, the small granular cells were also innervated by cholinergic nerve endings, which are postganglionic parasympathetic axon terminals and originate from the cardiac ganglionic cells of the heart ${ }^{26)}$.

Efferent synapses from the small granular cells to the somas or dendrities of the cardiac 
ganglionic cells have been reported by Matthews and Raisman ${ }^{27}$, Dail et al. ${ }^{28)}$, and Mekhail et $a .^{29)}$. The small granular cells had both afferent and efferent synapses with ganglionic cells and were believed to be interneurons that inhibited postganglionic cells ${ }^{2 \pi, 29)}$. From these findings, it was concluded that the small granular cells in cardiac ganglia function as inhibitory interneurons and modulate neurotransmission through the ganglia.

\section{Acknowledgements}

The authors thank Mr. C. Y. Jiang and Ms. S. C. Woo for their skillful technical assistance, and Ms. W. Y. Her for help in preparing the manuscript.

\section{References}

1) Kirby ML and Stewart DE: Development of ANS innervation to the avian heart. In: Developmental Neurobiology of the Autonomic Nervous System, Gootman PM (Ed), The Humana Press, Inc., Clifton, New Jersey, pp 135-158 (1986)

2) Le Douarin NM, Smith J and Le Lievre CS: From the neural crest to the ganglia of the peripheral nervous system. Annu Rev Physiol, 43: 653-671 (1981)

3) Liu KM and Inokuchi S: Ultrastructural study of the cardiac ganglia in prenatal rat. I. Cytogenesis. Showa Univ J Med Sci, 2: 45-56 (1990)

4) Papka RE: A study of catecholamine-containing cells in the hearts of fetal and postnatal rabbits by fluorescence and electron microscopy. Cell Tissue Res, 154: 471-484 (1974)

5) Papka RE: Studies of cardiac ganglia in pre- and postnatal rabbit. Cell Tissue Res, 175: 17-35 (1976)

6) Kirby ML, Weidman TA and McKenzie JW: An ultrastructural study of the cardiac ganglia in the bulbar plexus of the developing chick heart. Dev Neurosci, 3: 174-184 (1980)

7) Shvalev VN and Sosunov AA: Electron microscopy study of cardiac ganglia in human fetuses. J Auton Nerv Syst, 26: 1-9 (1989)

8) Shvalev VN and Sosunov AA: A light and electron microscopic study of cardiac ganglia in mammals. Z Mikrosk Anat Forsch, 99: 676-694 (1985)

9) Shvalev VN and Sosunov AA: Ultrastructure of cardiac ganglia in human fetuses. Z Mikrosk Anat Forsch, 102: 397-410 (1988)

10) Papka RE: Ultrastructural and fluorescence histochemical studies of developing sympathetic ganglia in the rabbit. J Anat, 134: 337-364 (1972)

11) Liu KM and Inokuchi S: Topographical and morphological studies of the cardiac ganglia in prenatal rat. Showa Univ J Med Sci, 1.2: 7-22 (1989)

12) Ahrunhosa R: Microperfusion fixation of embryos for ultrastructural studies. J Ultrastruct Res, 41: 176-188 (1972)

13) Rees RP, Bunge MB and Bunge RP: Morphologic changes in the neuritic growth cone and target neuron during synaptic junction development in culture. J Cell Biol, 68: 240-263 (1976)

14) Okado $\mathrm{N}$ : Onset of synapse formation in the human spinal cord. J Comp Neurol, 201: 211-219 (1981)

15) Hervonen A: Development of catecholamine storing cells in human foetal paraganglia and adrenal medulla. Acta Physiol Scand (Suppl), 368: 1-94 (1971)

16) Bunge MB, Bunge RP and Peterson ER: The onset of synapse formation in spinal cord cultures as studies by electron microscopy. Brain Res, 6: 728-749 (1967)

17) Richardson KC: Electron microscopic identification of autonomic nerve endings. Nature, 210: 756 (1966)

18) Gabella G: Fine structure of the myenteric plexus in the guinea-pig ileum. J Anat, 111: 69-97 (1972)

19) Ellison JP and Hibbs RG: An ultrastructural study of mammalian cardiac ganglia. J Mol Cell Cardiol, 8: 89-101 (1976)

20) Yamauchi A: Innervation of the vertebrate heart as studies with the electron microscopy. Arch Histol Jpn, 31: 83-117 (1969)

21) Jacobson M: Developmental Neurobiology. 2nd ed. Plenum Press, New York, p 60 (1978) 
22) Coupland RE and Weakly BS: Developing chromaffin tissue in the rabbit: An electron microscopic study. J Anat, 102: 425-455 (1968)

23) Taxi J, Derer $\mathbf{M}$ and Domich A: Morphology and histophysiology of SIF cells in the autonomic ganglia. In: Autonomic Ganglia, Elfvin L-G (Ed), John Wiley \& Sons, Chichester, Brisbane, Toronto, Singapore, pp 67-95 (1983)

24) Bjorklund A, Cegrell L, Falck B, Ritzen $\mathbf{M}$ and Rosengren E: Dopamine-containing cells in sympathetic ganglia. Acta Physiol Scand, 78: 334-338 (1970)

25) Coupland RE, Pyper AS and Hopwood D: A method for differentiating between adrenaline and noradrenaline-storing cells in the light and electron microscopy. Nature, 201: 1240-1242 (1964)

26) Jacobowitz D: Histochemical studies of the relationship of chromaffin cells and adrenergic nerve fibers to the cardiac ganglia of several species. J Pharmacol Exp Ther, 158: 227-240 (1967)

27) Matthews MR and Raisman G: The ultrastructure and somatic efferent synapses of small granularcontaining cells in the superior cervical ganglion. J Anat, 105: 255-282 (1969)

28) Dail WG, Evan AP and Eason HR: The major ganglion in the pelvic plexus of the male rat. A histochemical and ultrastructural study. Cell Tissue Res, 159: 49-62 (1975)

29) MeKhail NA, Nawar NNY and Khairallah PA: New synapses associated with the granule-containing cells of rat sympathetic ganglia. Acta Anat, 133: 102-106 (1988)

[Received May 21, 1990: Accepted August 14, 1990] 

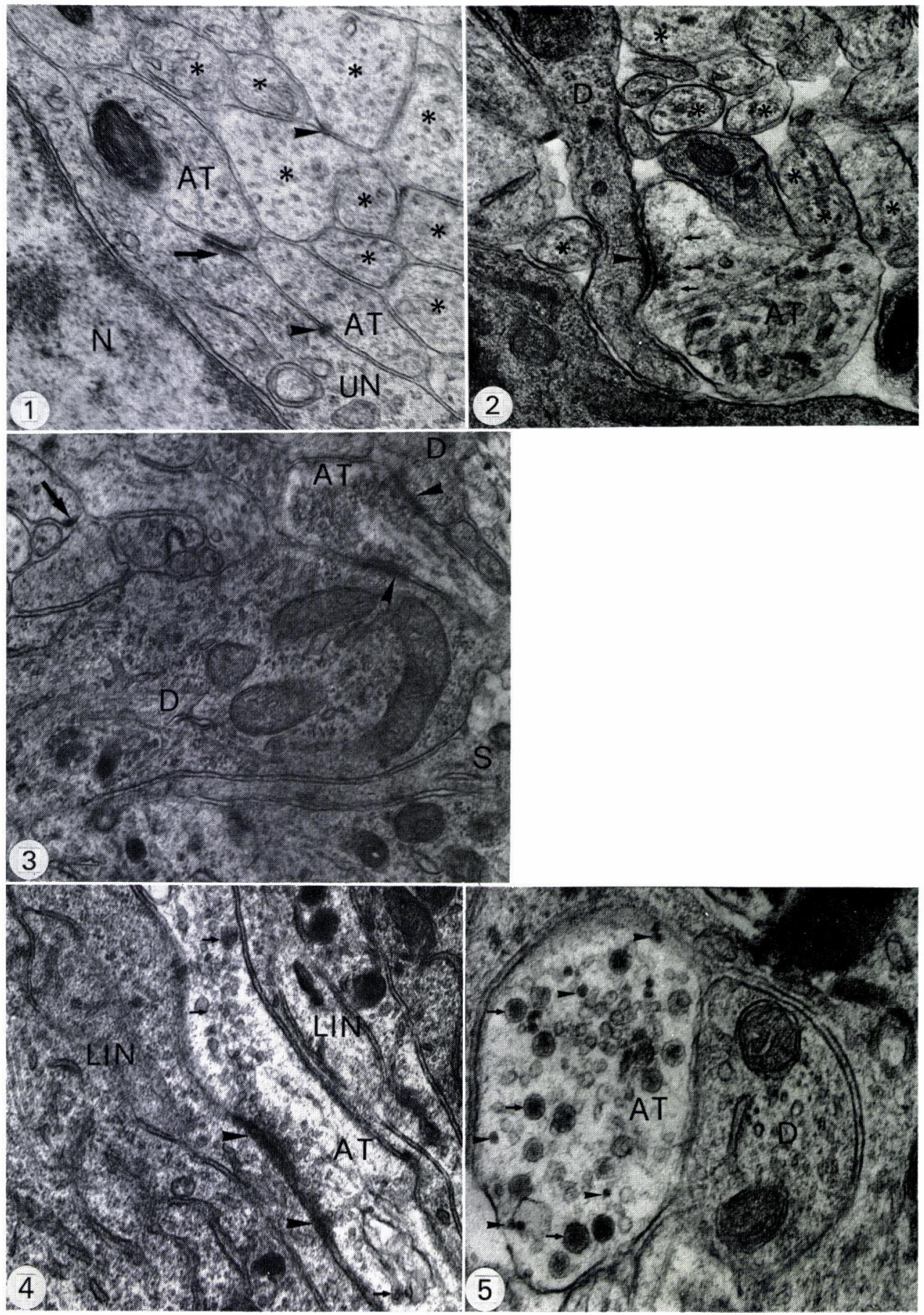

PLATE I 

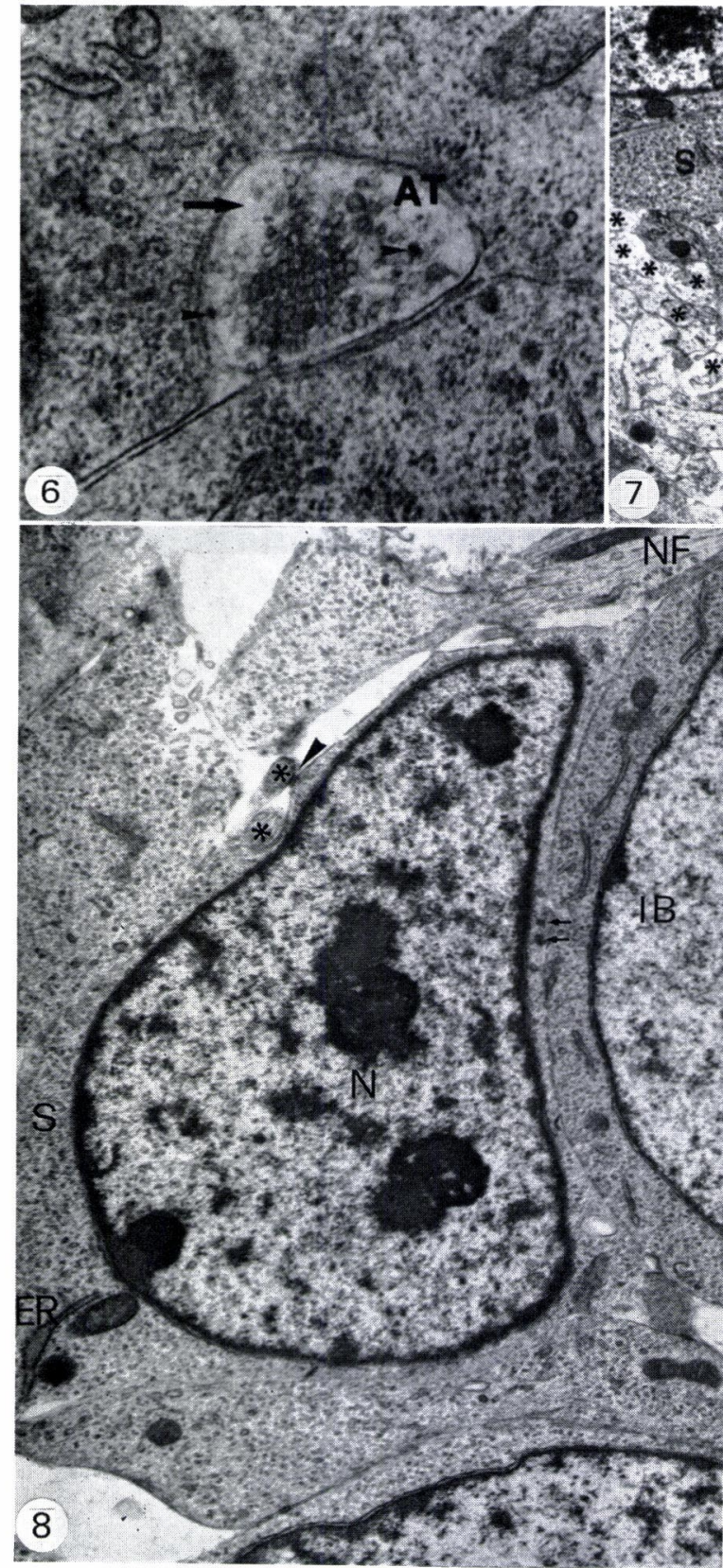
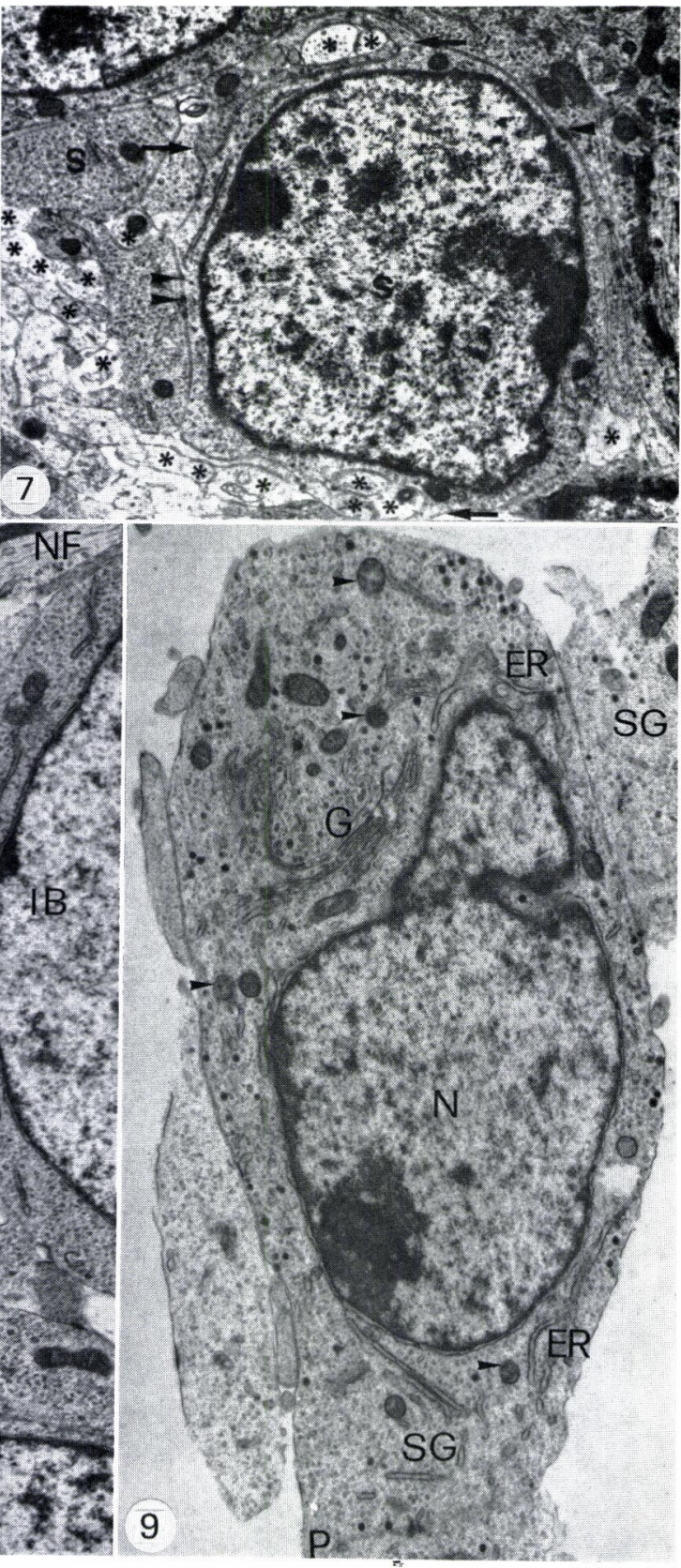

PLATE II 


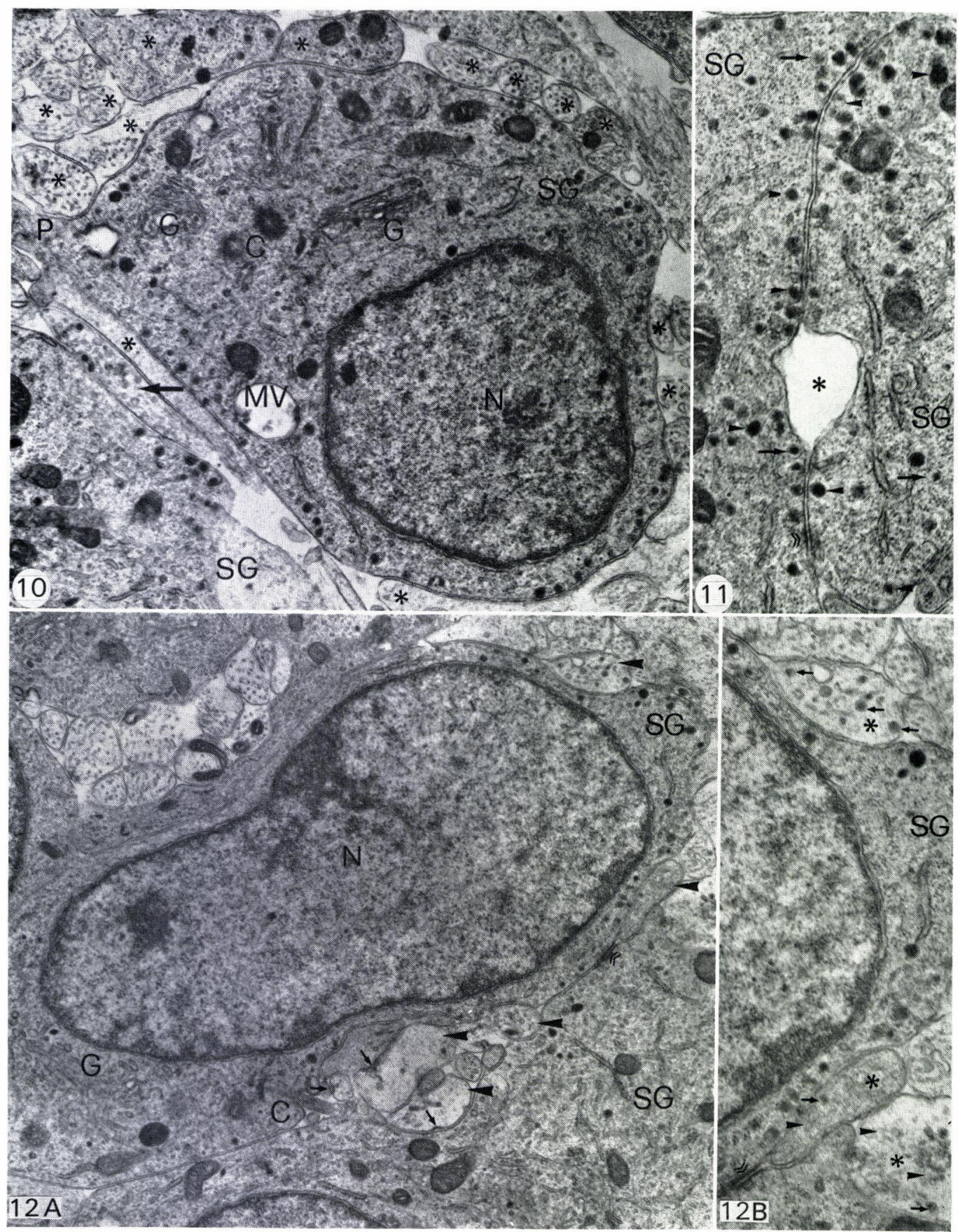

PLATE III 

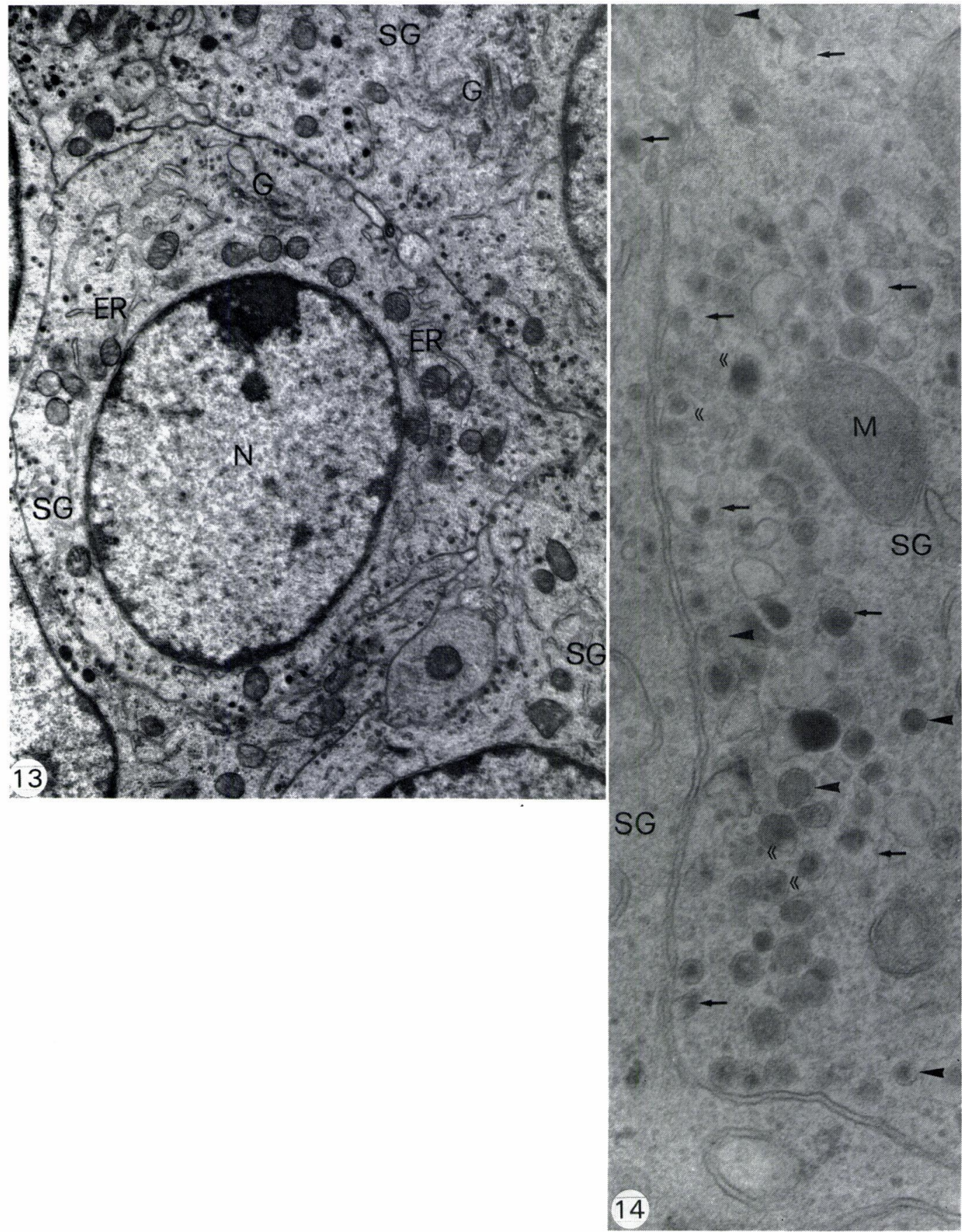

PLATE IV 


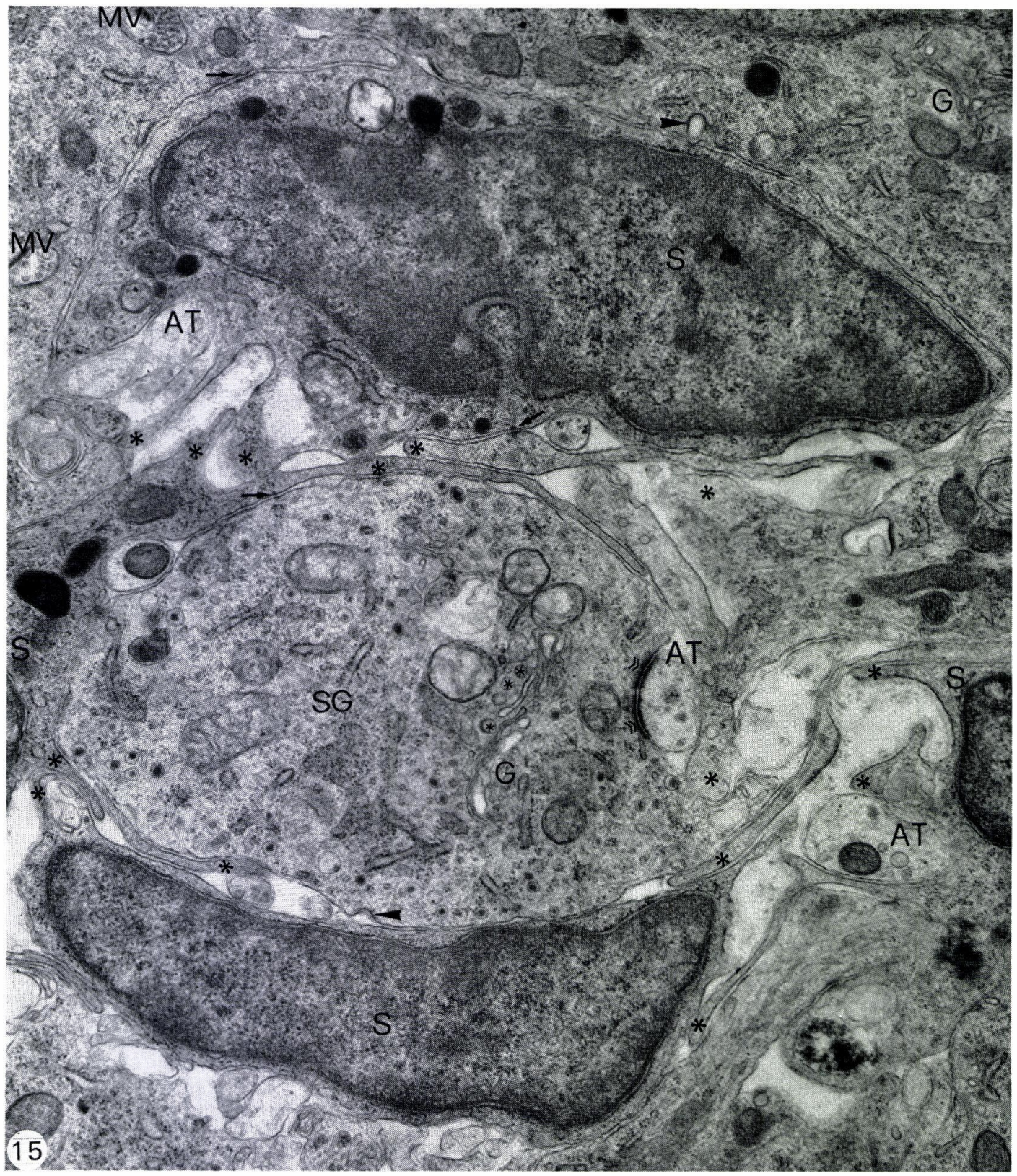

PLATE V 

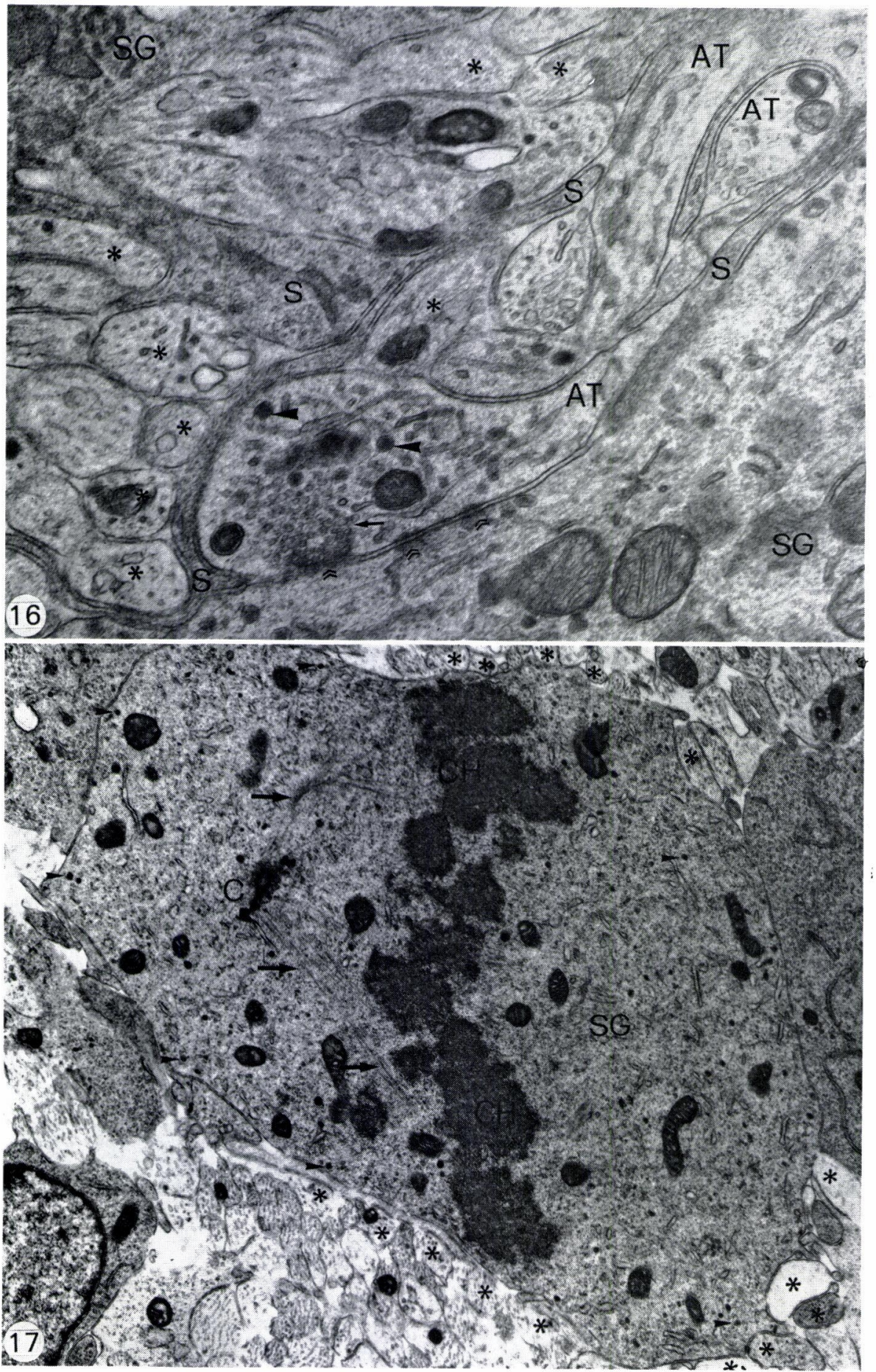

PLATE VI 


\section{EXPLANATIONS OF PLATES}

\section{PLATE I}

Fig. 1. The paramembranous electron-dense zone (arrow) and puncta adherens (arrowheads) appear on the plasmalemma of contacted sites of preganglionic nerve endings (AT) and undifferentiated cell (UN). Puncta adherens also can be seen between the nerve fibers (asterisks). Fourteen days of gestation, $\times 44000$.

Fig. 2. A nascent synapse (arrowhead) formed between the process (D) of the intermediate bipolar neuroblast and the axon terminal of a preganglionic nerve fiber (AT). Some small clear vesicles (arrows) are located close to the presynaptic membrane thickening. Eighteen-day fetus, $\times 44000$.

Fig. 3. One axon terminal (AT) contains numerous clear vesicles and forms axodendritic synapses (arrowheads) with two dendritic processes (D) of immature neuron. The axonal punctum (arrow) is found in an axon and has small submembraneous density. Twenty-one-day fetus, $\times 36000$.

Fig. 4. An axon terminal (AT) contains clear vesicles and large dense-core vesicles (arrows), and forms an axosomatic synapse (arrowheads) with the late immature neuron (LIN). Twenty-one-day fetus, $\times 44000$.

Fig. 5. The axon terminal (AT) contains glycogen granules (arrowheads), small clear vesicles, and large dense-core vesicles (arrows). D: dendrite. A fetus at eighteen day of gestation, $\times 72000$.

\section{PLATE II}

Fig. 6. One axon terminal (AT) contains numerous small clear vesicles (arrow) and a few glycogen granules (arrowheads), but does not form a synaptic contact with ganglionic nerve cell. Eighteen-day fetus, $\times 54000$.

Fig. 7. A young satellite cell (S) is characterized by an oval nucleus and a thin layer of cytoplasm. Within the cytoplasm, only a few organelles can be seen. Some short cytoplasmic processes (arrow) extend from the cell body and surround the nerve fibers (asterisks). Arrowhead shows the puncta adherens. Fourteen-day rat fetus, $\times 7600$.

Fig. 8. Close to the intermediate bipolar neuroblast (IB), a mature satellite cell (S) is characterized by a large semilunar shaped nucleus with heterogeneous distributed chromatin (N), few rough endoplasmic reticulum (ER) and mitochondria, and glycogen granules (arrows). A puncta adherens (arrowhead) can be seen between the axon (asterisk) and the satellite cell. NF: nerve fiber. Fighteen-day fetus, $\times 13500$.

Fig. 9. An early immature small granular cell (SG) is characterized by an irregularly shaped nucleus $(\mathrm{N})$, thin rough endoplasmic reticulum (ER), some round mitochondria (arrowhead), well developed Golgi complex (G) and peripherally distributed granular vesicles. A short process $(P)$ extends from the cell body. Fourteenday fetus, $\times 11500$. 


\section{PLATE III}

Fig. 10. The young small granular cells (SG) contains well developed Golgi complexes (G), multivesicular body (MV), centrioles (C), some mitochondria, and granular vesicles. Both cell body and process (P) are accompanied by axons (asterisks). Arrow indicate an axon terminal with synaptic vesicles. $\mathrm{N}$ : nucleus. Fifteen-day fetus, $\times 11400$.

Fig. 11. In a young small granular cell (SG), centrally located dense-core vesicles (arrow) and eccentrically located dense-core vesicles (arrowhead) are dispersed along the periphery of the cell body. The regional dilated intercellular space (asterisk) and puncta adherens (double arrowhead) appear between adjacent cells. Fifteen-day fetus, $\times 33600$.

Fig. 12. (A) Young small granular cells (SG) are closely abutted by axon terminals (arrowheads). Presynaptic thickness (arrow) can be seen in the axon terminals. Desmosome structure (double arrowhead) appears between the small granular cells. C: cilium, G: Golgi complex, N: nucleus. Fifteen-day fetus, $\times 19000$.

(B) Close to the young small granular cell (SG), the axon terminals (asterisks) contain glycogen granules (arrow), small clear vesicles (arrowheads), and large dense-core vesicles. Double arrowhead shows desmosome structure. Fifteen-day fetus, $\times 34000$.

\section{PLATE IV}

Fig. 13. Maturing small granular cell (SG) contains an oval shaped nucleus (N), many mitochondria (arrowhead), short rough endoplasmic reticulum (ER), well developed Golgi complexes (G) and numerous granular vesicles. Twenty-one-day fetus, $\times 6000$.

Fig. 14. In the cytoplasm of a maturing small granular cell (SG), three types of granular vesicles can be recognized. Type I has a centrally located dense core (arrowheads). Type II has an eccentrically located dense core (arrows). Type III is pleomorphic shaped and contains core with fine granular to spongy appearance (double arrowhead). M: mitochondria. Twenty-one-day fetus, $\times 45000$.

\section{PLATE V}

Fig. 15. Coated vesicles (small asterisks) are synthesized by the well developed Golgi complex (G) of a maturing small granular cell (SG), which is surrounded by axon terminals (AT) and branching processes (large asterisks) of satellite cells (S). An axon terminal forms an axosomatic synapse (double arrowhead) with maturing small granular cell. Arrowheads indicate the exocytotic sites of granular vesicles. MV: multivesicular body. Twenty-one-days of gestation, $\times 30000$.

\section{PLATE VI}

Fig. 16. An axon terminal (AT) contains a mixture of numerous small clear vesicles (arrow) and several large dense-core vesicles (arrowheads), and forms axosomatic synapse (double arrowhead) with a maturing small granular cell (SG). S: cytoplasmic process of a satellite cell. Asterisks: axons. Twenty-one-day fetus, $\times 42000$.

Fig. 17. A mitotic small granular cell (SG) contains granular vesicles (arrowheads) and is companied by numerous axons (asterisks). Spindle microtubules (arrows) connect the chromosomes $(\mathrm{CH})$ with the centriole (C). At 15 days of gestation, $\times 16200$. 